\section{Influência da aculturação na autopercepção dos idosos quanto à saúde bucal em uma população de origem japonesa}

\author{
Influence of acculturation on self-perceived \\ oral health among Japanese-Brazilian elderly
}

Daniel Afonso Hiramatsu 1

Laércio Joel Franco ${ }^{2}$

Nilce Emy Tomita 1
1 Faculdade de Odontologia de Bauru, Universidade de São Paulo, Bauru, Brasil.

2 Faculdade de Medicina

de Ribeirão Preto

Universidade de São Paulo, Ribeirão Preto, Brasil.

Correspondência

N. E. Tomita

Departamento de

Odontopediatria

Ortodontia e Saúde Coletiva,

Faculdade de Odontologia

de Bauru, Universidade

de São Paulo.

Al. Dr. Octávio Pinheiro

Brisolla 9-75,

Vila Universitária, Bauru, SP

17012-901, Brasil.

netomita@usp.br

\section{Abstract}

Utilizing a qualitative methodology, this study aimed to evaluate the influence of acculturation on the elderly population and self-perception of their oral health. The target population included 40 individuals, divided into two groups: firstand second-generation Japanese immigrants. Through recorded interviews, acculturation level was assessed for each group, as was its influence on attention to oral health and self-evaluation of oral health status and time elapsed since the last dental appointment. Acculturation affected both groups, although to a greater degree in second-generation Japanese-Brazilians. However, it does not interfere in self-perception of oral health by this population. The main individual care with their oral health included brushing, flossing, and soaking dentures in antiseptic solutions. In self-assessed oral health, the main complaints related to wearing dentures, and the time elapsed since the last dental appointment was 1.4 years for the nonedentulous and 6.3 years for the edentulous.

Acculturation; Self Concept; Aged

\section{Introdução}

O Brasil, à semelhança de diversos países do mundo, está envelhecendo rapidamente. A população idosa compõe, na atualidade, o segmento populacional que mais cresce em termos proporcionais. Considerando-se o início dos anos 80 até o final do século passado, observa-se um crescimento da população idosa em mais de $100 \%$, e até o ano 2025 o Brasil terá a sexta maior população idosa do mundo em números absolutos, com mais de 30 milhões de pessoas nessa faixa, representando quase $15 \%$ da população total 1 .

Em se tratando de odontologia, Ettinger $2 \mathrm{e}$ Kiyak \& Mulligan 3 relatam que um dos principais critérios utilizados para se identificar um idoso bem sucedido quanto à saúde é pela manutenção, por toda sua vida, de sua dentição natural, saudável e funcional, incluindo todos os aspectos sociais e benefícios biológicos, tais como a estética, o conforto, a habilidade para mastigar, perceber sabores e falar.

A saúde e, como parte dela, a saúde bucal, representa um fator decisivo para a manutenção, na velhice, de uma boa qualidade de vida, a qual pode ser definida como a ausência de dor, mantendo um estado funcional saudável nos domínios físico, social e psicológico e um autoconceito positivo 4 .

Marcus et al. 5, em pesquisas realizadas com adultos e idosos americanos, observaram que 
o número médio de dentes remanescentes pode variar consideravelmente nos indivíduos idosos, segundo alguns fatores tais como nível educacional, salário e nível sócio-econômico. Os indivíduos com mais de 65 anos que tinham os mais baixos índices de escolaridade e menores proventos também apresentavam os mais altos índices de edentulismo, evidenciando que a perda de elementos dentários é uma questão que deve ser percebida pelo seu componente social.

Componentes sócio-culturais têm especial relevância na abordagem da população de origem japonesa e do processo de imigração para o Brasil, que atualmente abriga a maior população nikkei residente fora do Japão. Essa imigração teve início em 1908, originada pela simultânea necessidade de mão-de-obra no Brasil e pela superpopulação e crise agrícola no Japão, tendo atingido seu ápice entre os anos 20 e 30. Esse fato traz consigo conseqüências que podem ser percebidas até os dias de hoje e ajuda a entender a identidade étnica desses imigrantes e seus descendentes.

Para grupos étnicos frutos da imigração, essa identidade étnica se transforma em virtude não só das mudanças da sociedade hospedeira, mas também das novas gerações de descendentes, que se distanciam da cultura de origem. A cultura e os costumes dos ascendentes, por sua vez, também podem sofrer influências importantes no país hospedeiro, o que caracteriza o processo de aculturação, o qual é nitidamente observado em populações de imigrantes no Brasil, em especial a população japonesa.

Alguns dados populacionais comprovam essa tendência: os casamentos interétnicos já representam cerca de $46 \%$ do total. Em torno de $28 \%$ dos nikkei são mestiços, um número que aumenta progressivamente com as gerações: $6 \%$ são mestiços na segunda geração, $42 \%$ na terceira e $62 \%$ na quarta geração. No que se refere diretamente ao comportamento religioso, quase $60 \%$ já se declaram católicos e somente cerca de $25 \%$ ainda se dizem praticantes de alguma religião japonesa 6 .

Neste trabalho, procuramos apresentar, por meio de abordagem qualitativa, alguns dos aspectos relativos ao nível de aculturação em que se encontra cada uma das gerações dos imigrantes japoneses aqui estudada (primeira e segunda gerações).

Este estudo tem por objetivo verificar a autopercepção, ou seja, quais as queixas e os cuidados com a saúde bucal que possui a população idosa de origem japonesa e avaliar se o edentulismo apresenta alguma influência sobre o julgamento que o idoso, de primeira ou segunda geração, faz de sua condição bucal.

\section{Método}

O protocolo de pesquisa foi aprovado pelo Comitê de Ética em Pesquisa da Faculdade de Odontologia de Bauru, Universidade de São Paulo (USP), atendendo à Resolução n. 196/96 do Conselho Nacional de Saúde.

\section{População de estudo}

Um outro estudo epidemiológico com delineamento transversal foi iniciado em outubro de 1999 e concluído em dezembro de 2000, com universo de 1.315 indivíduos. As não-participações decorreram de recusas, óbitos e indivíduos não localizados, resultando em 458 perdas $(25,8 \%)$. Foram identificados $35,7 \%$ de edêntulos totais neste grupo populacional.

Para a identificação da população-alvo, foi realizado um censo, em 1998, sob coordenação do Departamento de Medicina Preventiva, Universidade Federal de São Paulo (UNIFESP), com a colaboração do Clube Cultural Nipo-Brasileiro de Bauru. Cadastrou-se a totalidade de indivíduos nipo-brasileiros da primeira geração (is$s e i$ ) e da segunda geração (nisei), com idade acima de trinta anos, de ambos os sexos, residentes no Município de Bauru, São Paulo, Brasil, resultando em 1.773 indivíduos, que foram convidados a participar de estudos sobre a saúde da população nikkei 7 .

Para o presente estudo, foram definidos, em processo de amostragem aleatória simples, quarenta indivíduos desta população. Estes pertenciam às primeira e segunda gerações, na faixa etária de 60 a 80 anos, de ambos os sexos, residentes no Município de Bauru, os quais foram divididos em quatro grupos, com dez indivíduos cada. Estes grupos apresentaram os critérios de inclusão: issei com dentes, issei edêntulo, nisei com dentes e nisei edêntulo.

Considerando a importância do crescimento da população de idosos e da grande variedade étnica presente no Brasil, associada ao processo de aculturação por que passam essas populações, e em especial os imigrantes japoneses e seus descendentes, optou-se por uma população-alvo composta por idosos nipo-brasileiros, a fim de se compreenderem os reflexos sociais deste processo.

\section{Exame das condições bucais}

No estudo anterior de Tomita et al. 7, foram aplicados os índices CPOD (cárie dentária), IPC (Índice Periodontal Comunitário) e PIP (Índice de Perda de Inserção Periodontal), utilizando- 
se metodologia proposta pela Organização Mundial da Saúde 8 . No presente trabalho, foram considerados os dados relativos à dicotomia presença-ausência total de dentes na boca.

\section{Avaliação de aspectos sócio-culturais}

Foram utilizados métodos qualitativos para coleta de informações e análise de discurso. Realizaram-se entrevistas domiciliares, com os indivíduos que preencheram os critérios de inclusão para cada grupo.

Fez parte do processo de coleta de informações a entrevista utilizando roteiro semi-estruturado. O roteiro foi constituído de questões sobre a freqüência de participação em eventos da cultura japonesa, a manutenção do idioma japonês pelos próprios imigrantes ou gerações subseqüentes e a religião praticada. Verificaram-se também, além dos aspectos sócio-culturais, os conceitos sobre as condições de saúde bucal e os cuidados com ela (Figura 1).

Utilizou-se como estratégia metodológica em pesquisa qualitativa a construção do "discurso do sujeito coletivo" 9, que consiste numa forma qualitativa de representar o pensamento de uma coletividade, agregando em um discur- so-síntese os conteúdos discursivos semelhantes emitidos por pessoas distintas. Cada indivíduo entrevistado, escolhido com base em critérios de representatividade social, contribui com sua cota de fragmento de pensamento para o pensamento coletivo 10 .

Este procedimento metodológico pressupõe a definição, a partir de uma perspectiva empírica, de que o caráter coletivo do pensamento social é a quantidade de escolhas de um determinado conjunto de indivíduos pertencentes a uma determinada coletividade e, apesar de expresso de forma individualizada, é socialmente compartilhado, traduzindo a natureza do pensamento coletivo 10 .

Os depoimentos colhidos individualmente tiveram como objetivo coletar, através da fala dos atores sociais, informações que permitissem o acesso a dados da realidade de caráter subjetivo, como idéias, crenças ou maneiras de atuar 11 .

\section{Resultados}

A distribuição etária do grupo avaliado é apresentada na Tabela 1. Os indivíduos de primeira

Figura 1

Roteiro da entrevista

Universidade de São Paulo

Faculdade de Odontologia de Bauru

Departamento de Odontopediatria, Ortodontia e Saúde Coletiva

Data _L_ I

Nome:

Ocupação:

Escolaridade:

Estado familiar: Posição na família:

Questões relacionadas ao processo de aculturação:

01. Você participa de eventos relacionados à cultura japonesa? Com qual freqüência?

02. Que língua você usa para conversar com sua família?

03. Qual a sua religião?

Questões relacionadas à autopercepção:

04. Quais os cuidados que você toma quanto à saúde bucal?

05. Como avalia sua atual condição bucal?

06. Quando foi sua última visita ao dentista? 
Tabela 1

Média etária (anos) dos entrevistados segundo geração e edentulismo.

Bauru, São Paulo, Brasil, 2004.

\begin{tabular}{|c|c|c|c|c|c|c|c|c|}
\hline & \multicolumn{4}{|c|}{ Issei } & \multicolumn{4}{|c|}{ Nisei } \\
\hline & \multicolumn{2}{|c|}{ Masculino } & \multicolumn{2}{|c|}{ Feminino } & \multicolumn{2}{|c|}{ Masculino } & \multicolumn{2}{|c|}{ Feminino } \\
\hline & Média & $\mathrm{n}$ & Média & $\mathrm{n}$ & Média & $\mathrm{n}$ & Média & $\mathrm{n}$ \\
\hline Com dentes & 65,5 & 7 & 63,0 & 3 & 59,6 & 3 & 56,0 & 7 \\
\hline Edêntulos & 71,5 & 2 & 67,0 & 8 & 60,0 & 2 & 66,7 & 8 \\
\hline
\end{tabular}

geração apresentam média etária mais elevada que os de segunda geração, em ambos os sexos.

\section{Alguns aspectos relativos à aculturação}

Pôde-se observar que o processo de ocidentalização ou aculturação abrange de maneira generalizada os imigrantes japoneses e seus descendentes. Porém, esse processo se dá de maneira mais intensa nos indivíduos pertencentes à segunda geração (nisei) quando comparados aos da primeira geração (issei).

\section{Participação em eventos da cultura japonesa}

No grupo issei, observa-se que as atividades culturais são desenvolvidas com participação ativa em espaços sociais como o Clube Cultural Nipo-Brasileiro de Bauru, onde são desenvolvidas atividades em grupos, de acordo com sua faixa etária (grupo da terceira idade), sexo (grupo das senhoras) ou estado civil (grupo dos casais).

Há também a oportunidade de participar de excursões e eventos comemorativos, nos quais as expressões da cultura japonesa, por meio da música (karaokê) e da culinária (sukiaki), são desenvolvidas.

Entre os indivíduos pertencentes à segunda geração, a parcela dos entrevistados que se mostrou mais assídua a esses eventos relatou participar de atividades mensais ou quinzenais. Nota-se uma diferença ao comparar este grupo ao da primeira geração, que relatou participar em eventos semanais e diários, não só do clube, mas também de atividades religiosas.

Observa-se, entre os nisei, uma participação mais voltada a eventos anuais (Obon Odori, Undokai), denotando que a segunda geração, de maneira geral, tem uma participação menos ativa no que se refere a eventos da cultura japonesa quando comparada à primeira geração. Isso sugere algum distanciamento da cultura japonesa por parte deste grupo quando comparado aos issei.

\section{$\underline{\text { Idioma }}$}

Tanto para o grupo issei, quanto para o grupo nisei, os indivíduos que relataram utilizar predominantemente o idioma português representaram a maioria. Embora grupo issei tenha apresentado o maior número de respostas relatando que o idioma japonês prevalece no ambiente familiar, observa-se que o processo de aculturação ocorre em ambas as gerações, porém com maior intensidade na segunda, em que o idioma japonês é utilizado com baixa freqüência ou em situações especiais.

Alguns indivíduos do grupo nisei declararam utilizar o idioma japonês somente durante a conversa com os indivíduos mais velhos da comunidade. Dessa maneira, a conversação em idioma japonês tem espaço restrito, deixando de relegar às gerações posteriores esse importante traço da cultura.

Aqueles que relataram prevalecer o idioma japonês nas conversas com a família foram minoria no grupo nisei, o que mostra que, com o passar das gerações, esse idioma vai sendo cada vez menos utilizado. As respostas em que os indivíduos deste grupo relataram utilizar o idioma japonês somente na conversação com os mais velhos estiveram presentes de maneira importante, mostrando a influência que os indivíduos da primeira geração exercem sobre os da segunda geração, já que estes procuram conservar o idioma japonês na conversa com os mais velhos. Concomitantemente, o processo de ocidentalização mostra marcas que se vêem na ausência de preocupação em utilizar o idioma japonês com os seus filhos e netos.

\section{Religião}

O relato da escolha de religiões de origem judaico-cristã ou filosofias de origem ocidental é observado no grupo nisei, ainda que parentes mais velhos, pais e avós, sejam praticantes de religiões orientais.

Para o grupo issei, foi predominante a escolha de uma religião japonesa, evidenciando que a cultura do país de origem encontra-se ainda presente no cotidiano desses indivíduos. Entre os nisei, evidencia-se a incorporação de traços da cultura ocidental, como a religião.

Percebe-se, portanto, que a relação com os parentes mais velhos, em sua maioria da primeira geração, freqüentemente é o que mantém os indivíduos do segundo grupo mais próximos à sua cultura de origem. 


\section{Percepção quanto à saúde bucal}

Considerando as diferenças culturais entre os dois grupos, issei e nisei, busca-se entender de que maneira a população-alvo do presente estudo vê a si própria, por meio de sua percepção sobre saúde bucal e seus cuidados, avaliando quais são os fatores que influenciam na decisão quanto ao tratamento odontológico.

Os principais cuidados citados entre os indivíduos do grupo dos que possuem dentes foram a escovação, seguida por utilização do fio dental e enxaguatório bucal.

Entre os sujeitos edêntulos, os principais cuidados citados foram: escovação, imersão da prótese em produtos químicos e bochechos com enxaguatórios bucais:

"Eu escovo a dentadura com pasta, duas, três vezes por dia. Alguma vez depois da comida" (Edêntulos). "Eu coloco de noite [a dentadura] no bicarbonato e deixo de molho. De noite (...) eu escovo o dente, eu ponho bicarbonato na vasilha e deixo lá, no outro dia coloco de novo" (Edêntulos). "Eu faço bochecho duas vezes ao dia, de manhã e de tarde escovo a dentadura e deixo a dentadura de molho na água" (Edêntulos)

Os indivíduos edêntulos relataram conhecimentos sobre os cuidados com a saúde bucal baseados em experiências pessoais do dia-adia, através do contato com vizinhos, parentes, amigos e propagandas de produtos para higiene bucal veiculadas nos meios de comunicação em massa (televisão, revistas e jornais):

“Eu escovo, porque a dentadura eu fico à vontade que dá pra tirar, é que eu não gosto que fique nenhuma sujeirinha. E até saiu aquela propaganda do Corega, então eu experimentei comprar, e coloco ali e ele é uma coisa efervescente, e a gente tem que limpar, e é isso, se tem outro processo eu não sei” (Edêntulos). “... agora me ensinaram a deixar de molho, fica limpinho, minhas colegas que ensinaram, aquelas manchinhas pretas, sai tudo, deixa de molho no Varek, quando começa a amarelar, coloca e sai tudo. Deixa de molho, depois de meia hora eu vou escovar e sai tudo" (Edêntulos).

A maioria dos entrevistados relatou não possuir queixas quanto à atual condição bucal. Entre os indivíduos que apresentaram alguma queixa, pôde-se perceber diferenças entre as percepções daqueles pertencentes ao grupo dos que possuem dentes em relação ao grupo dos edêntulos.

Há percepção de desconforto com a prótese dentária parcial (fixa ou removível) entre os indivíduos com dentes, referindo, sobretudo, alguma desadaptação ou desgaste da peça protética:
“... eu uso a ponte, só que a minha ponte eu não sei, eu não me adaptei muito, por isso que eu estou sem, eu uso, mas principalmente pra comer eu não costumo, a ponte é em baixo, daquelas que saem, eu não acostumei, parece que quando eu mastigo entra 'gohan' [arroz] por baixo, fora que ela incomoda, só uso assim quando vou ao médico pra não ficar sem, mas o resto, se eu for comer fora não dá, porque como eu vou comer assim se incomoda" (Indivíduos com dentes).

A preocupação estética mostra-se presente, aliada a queixas quanto a questões funcionais relacionadas à fala e mastigação:

"Podia estar melhor, se tivesse feito um tratamento que ficasse esteticamente bem" (Indivíduos com dentes). "Tenho problema com a mastigação, porque embaixo não tenho os dentes do fundo, só tem os dentes da frente. Meu problema é a mastigação ..." (Indivíduos com dentes). "Eu, por exemplo, só posso mastigar desse lado aqui" (Indivíduos com dentes).

As queixas relatadas por indivíduos edêntulos foram principalmente relacionadas ao uso de prótese total, por sua não-adaptação funcional ou pelo fato de não se acostumarem com o uso desse tipo de prótese:

"Está um pouquinho frouxa (...) agora quando eu mastigo escapa um pouco" (Edêntulos). "Podia estar melhor, mas esse aí eu preciso refazer porque é muito antigo e faz tempo que eu fiz. $O$ problema é só o desgaste mesmo" (Edêntulos). "Não é que machuca, dói, tem vez que eu fico um dia assim, mas aí incomoda e eu tiro, eu não consigo me acostumar com a dentadura" (Edêntulos).

O tempo decorrido desde a última visita do indivíduo ao cirurgião-dentista e a motivação dessa visita foram achados com diferenças importantes no comportamento do grupo de edêntulos e dos que possuíam dentes:

"Semana passada. Quando tem problema a gente telefona, marca hora, dia e vai" (Indivíduos com dentes). "Faz uns dois a três anos, estou precisando voltar ...” (Indivíduos com dentes). "Uns quinze dias atrás, é que eu comecei faz uns seis meses, então estou fazendo uma revisão geral aos poucos" (Indivíduos com dentes).

Tratamentos periodontais, restauradores e profiláticos foram bastante citados como os motivos da última visita ao cirurgião-dentista entre os portadores de dentes:

"... eu estou em tratamento de gengiva" (Indivíduos com dentes). "Trincou um dente" (Indivíduos com dentes). “... minha filha [cirurgiãdentista] fez uma limpeza, polir os dentes ...” (Indivíduos com dentes).

A troca ou ajuste da prótese foram os motivos mais citados para a última visita ao cirurgião-dentista: 
“Fui uma vez depois que coloquei, estava pegando muito então deu uma raspadinha e nunca mais fui (...) eu só vou ao dentista pra trocar a dentadura” (Edêntulos). “... pra colocar essa última dentadura (...) a última vez que fui foi pra trocar a dentadura" (Edêntulos).

A média de tempo decorrido desde a última visita ao cirurgião-dentista dos entrevistados mostra que os indivíduos que ainda possuem os dentes são bem mais assíduos ao cirurgiãodentista do que os dos grupos dos edêntulos, já que a média de tempo dos primeiros ficou entre 1,1 e 1,7 ano, enquanto a dos segundos ficou entre 6 e 6,5 anos.

O principal motivo das visitas por parte do grupo dos que possuíam dentes foi a realização de tratamentos restauradores, periodontais e profiláticos, mostrando a preocupação desses indivíduos com a manutenção dos dentes. Por outro lado, o principal motivo das visitas pelo grupo dos edêntulos foi o ajuste ou troca da prótese total, revelando que ainda persiste a idéia da prótese total como tratamento definitivo.

\section{Discussão}

São evidenciadas as diferenças com relação aos aspectos relativos à participação em eventos da cultura japonesa, idioma e religião nas respostas dos sujeitos, segundo a geração. Demonstra-se assim que, apesar de ambas as gerações mostrarem, em seus percursos de vida, influências do processo de aculturação, o indivíduo pertencente à segunda geração apresenta-se mais afastado da cultura de origem.

Neste tipo de abordagem, encontra-se alguma dificuldade com relação à fidedignidade das respostas obtidas quando se trata dos cuidados com a saúde bucal e não há como aferir se os entrevistados relatam o que efetivamente fazem 12 . Geralmente, respondem baseados em seus conhecimentos sobre esses cuidados, não descrevendo os procedimentos que realizam com relação à saúde bucal, mas sim discursando sobre conhecimentos odontológicos adquiridos ao longo da vida.

Ainda que se reconheçam as limitações desse tipo de pergunta, esta abordagem adequouse à finalidade do presente estudo, tendo em vista que o objetivo da questão não se limitava ao comportamento dos entrevistados com relação à saúde bucal; buscava, também, entender seus conhecimentos e conceitos sobre os cuidados com a boca.

Para a questão dos cuidados dispensados à saúde bucal, não houve diferenças entre as respostas dos indivíduos pertencentes às primeira e segunda gerações. As diferenças nas idéias centrais deram-se entre os indivíduos edêntulos quando comparados com os indivíduos que possuíam dentes.

Apesar de não se poder afirmar com certeza que o grupo dos que tinham dentes realmente se valeram dos métodos citados, pôde-se perceber que os sujeitos referem não só uma consciência da existência desses métodos, como também o valor da higiene oral para a manutenção da saúde da boca.

De acordo com Budtz \& Jorgensen 13, um regime adequado de limpeza das próteses totais deve ser desenvolvido tanto para remover e prevenir o acúmulo de microrganismos (incluindo Candida albicans), quanto para retirar mucina, restos alimentares e cálculo, fatores que podem levar a graus variados de inflamação da mucosa subjacente à prótese dentária, comprometer a estética e causar mau hálito. Segundo Jagger \& Harrison 14, o método mais eficiente na remoção da placa bacteriana da superfície de próteses totais ou removíveis é a escovação associada à imersão em produtos químicos adequados.

A informação sobre cuidados com a saúde bucal é um elemento presente entre os entrevistados, seja para os com dentes, seja para os edêntulos. Todavia, isso não nos permite afirmar que esses conhecimentos sejam necessariamente colocados em prática 12 .

A falta de orientação adequada pode resultar em condutas como exagerar na limpeza das próteses dentárias, utilizando produtos que as deterioram, como pastas abrasivas, hipocloritos, ácidos caseiros concentrados ou fervura da prótese. Em contrapartida, alguns indivíduos apenas enxáguam as peças protéticas após o uso ou realizam sua escovação com pouca freqüência.

Frequentemente, a avaliação das condições de saúde que utiliza critérios eminentemente normativos não leva em consideração aspectos culturais e sociais que influenciam o padrão de queixas dos indivíduos. Conhecer a percepção destes quanto à própria condição de saúde bucal contribui para compreender seus comportamentos e para estimular a promoção de cuidados apropriados.

A consciência da condição bucal é um importante indicador de saúde, porém a autoavaliação dessa condição aparentemente contrasta com a condição clínica, especialmente em idosos, que podem ter a percepção afetada por valores pessoais, como a crença de que algumas dores e incapacidades são inevitáveis nessa idade, o que pode levar a pessoa a superestimar sua condição bucal. Percebe-se, en- 
tão, que o paciente avalia sua condição bucal com critérios diferentes dos do profissional, mas esses indicadores subjetivos, em especial a autopercepção, podem ser usados como mais um instrumento de avaliação que complementa as informações clínicas e possibilita identificar pessoas ou populações que necessitam de ações curativas, preventivas ou educativas 15 .

Constata-se que o uso de próteses é um dos principais fatores de descontentamento entre os idosos, ao abordar a saúde bucal, considerando as respostas tanto dos indivíduos edêntulos, quanto dos que possuem dentes e que utilizavam algum tipo de prótese parcial. Apesar dos avanços tecnológicos excepcionais na área da reabilitação odontológica, queixas relativas ao uso de próteses dentárias totais ou parciais, como o desgaste e a dificuldade de adaptação do indivíduo à prótese, mostram que o acesso a estes avanços ainda constitui uma realidade distante.

Entre os indivíduos edêntulos, a freqüência de visitas ao cirurgião-dentista mostra-se inferior àquela referida pelos indivíduos com dentes. Tendo em vista que, para usuários de próteses totais, são indicados retornos anuais e reembasamentos ou substituição das próteses aproximadamente a cada cinco anos 16, o intervalo decorrido entre a instalação da prótese e o momento atual registra longos períodos sem qualquer modalidade de assistência odontológica.

\section{Resumo}

O presente estudo busca avaliar a influência da aculturação da população idosa na autopercepção de sua saúde bucal, utilizando metodologia qualitativa. A população-alvo foi composta por quarenta indivíduos divididos em dois grupos principais, o dos pertencentes à primeira geração de imigrantes japoneses e o da segunda geração. Mediante entrevista gravada, foi avaliado o nível de aculturação de cada grupo e sua influência sobre os cuidados tomados com a saúde bucal, a auto-avaliação da condição bucal e o tempo decorrido desde a última visita ao cirurgião-dentista. $O$ processo de aculturação atinge ambos os grupos, porém com maior intensidade o grupo da segunda geração; isso, no entanto, não interfere na autopercepção da saúde bucal desta população. Os principais cuidados tomados com a saúde bucal foram: escovação, uso do fio dental e imersão da prótese em soluções antisépticas. Na auto-avaliação da condição bucal, as principais queixas se deram em relação ao uso de próteses; o tempo decorrido desde a última visita ao cirurgião-dentista foi, em média, de 1,4 ano para os não edêntulos e 6,3 anos para os edêntulos.

\section{Considerações finais}

São evidentes os reflexos sociais do processo de aculturação nos descendentes de imigrantes japoneses no Brasil. Estudar esse processo através das falas dos atores que vivenciaram essas realidades tem por foco adequar-se à subjetividade das experiências vividas e dos conceitos sobre saúde-doença bucal relatados pela população-alvo deste estudo.

Embora não tenha sido encontrada diferença na autopercepção da saúde bucal entre os grupos issei e nisei, este trabalho mostrou que a percepção dos indivíduos idosos nipo-brasileiros refletiu uma situação de escassez de cuidados quanto à saúde bucal, revelando que ações de promoção e educação voltadas para esta parcela da população se fazem necessárias.

A conscientização da população quanto às questões da saúde bucal do idoso, por meio de suas representações, queixas e padrão de cuidados, possibilita uma discussão ampliada visando à implantação de programas de saúde bucal para a terceira idade, que constitui um dos problemas de saúde no Brasil a ter espaço na agenda de saúde pública.

\section{Colaboradores}

D. A. Hiramatsu realizou a busca bibliográfica, as entrevistas e transcrição das respostas e participou da discussão e redação do artigo. L. J. Franco participou da discussão. N. E. Tomita contribuiu com a concepção teórica e discussão.

\section{Agradecimentos}

À Fundação de Amparo à Pesquisa do Estado de São Paulo (processos: n. 03/05743-0 e n. 03/05742-3) pelo financiamento.

Aculturação; Auto-Imagem; Idoso 


\section{Referências}

1. Cormack E.F. A saúde oral do idoso. http://www. odontologia.com.br/geriatria (acessado em 28/ Abr/2002).

2. Ettinger RL. Oral diseases and its effects on the quality of life. Gerodontics 1987; 3:103-6.

3. Kiyak HA, Mulligan K. Studies of the relationship between oral health and psychological wellbeing. Gerodontics 1987; 3:109-12.

4. Fanny J. Atenção a idosos. In: Pinto VG, organizador. Saúde bucal coletiva. São Paulo: Editora Santos; 2000. p.120-7.

5. Marcus SE, Kaste LM, Brown LJ. Prevalence and demographic correlates of thooth loss among the elderly in the United States. Spec Care Dentist 1994; 14:123-7.

6. Shoji R. O budismo étnico na religiosidade nikkey no Brasil: aspectos históricos e formas de sobrevivência social. Revista de Estudos da Religião 2002; 4:47-80.

7. Tomita NE, Chinellato LEM, Pernambuco RA, Lauris JRP, Franco LJ. Condições periodontais e diabetes mellitus na população nipo-brasileira. Rev Saúde Pública 2002; 36:607-13.

8. World Health Organization. Oral health surveys: basic methods. $4^{\text {th }}$ Ed. Geneva: World Health Organization; 1997.
9. Lefèvre F, Lefèvre AMC. O discurso do sujeito coletivo: um novo enfoque em pesquisa qualitativa (desdobramentos). Caxias do Sul: Educs; 2003.

10. Lefèvre F, Lefèvre, AMC. O pensamento coletivo como soma qualitativa. São Paulo, 2003. http:// hygeia.fsp.usp.br/quali-saude/soma (acessado em 30/Mai/2004).

11. Minayo MCS. O desafio do conhecimento: pesquisa qualitativa em saúde. São Paulo: Editora Hucitec/Rio de Janeiro: ABRASCO; 2000.

12. Figueira DF. Self-reported denture hygiene of a sample of edentulous attendees at a University dental clinic and the relationship to the condition of the oral tissues. Gerodontology 2004; 21:226-8.

13. Budtz E, Jorgensen E. Materials and methods for cleaning dentures. J Prosthet Dent 1979; 42:619-23.

14. Jagger DC, Harrison A. Denture cleansing - the best approach. Br Dent J 1995; 178:413-7.

15. Silva SRC, Fernandes RAC. Autopercepção das condições de saúde bucal por idosos. Rev Saúde Pública 2001; 35:349-55.

16. Marchini L, Cunha VPP, organizadores. Prótese total: procedimentos clínicos e laboratoriais. Curitiba: Editora Maio; 2002.

Recebido em 08/Jul/2005

Versão final reapresentada em 14/Dez/2005

Aprovado em 19/Dez/2005 